\title{
Epithelial-Myoepithelial Carcinoma of Parotid Gland: A Cytological Challenge with Histological Correlation
}

Iván Fernández-Vega*, Nelson Fuentes-Martínez, Guillermo E Mendoza, Jorge Santos-Juanes and Florentino Fresno-Forcelledo

Pathology Department of Central University Hospital of Asturias, Oviedo, Spain

\begin{abstract}
Background: Epithelial-Myoepithelial Carcinoma (EMC) is a rare type of malignant tumor of salivary gland accounting for less than $1.5 \%$ of all salivary neoplasms. Differential diagnosis of this tumor is complicated, especially by cytological examinations.

Case: We present the case of an 86-year-old female who presented clinically with a bulky lesion behind her right ear. Fine needle aspiration cytology with immunocytochemistry has been performed and the patient was diagnosed with a biphasic neoplasm, epithelial-myoepithelial, highly suggestive of EMC. She underwent a wide surgical excision and diagnostic was confirmed by histological examinations, which showed a tumor composed of ducts with double cell lining surrounded by a basement membrane in a sclerotic stroma. Immunohistochemistry was carried on to highlight the biphasic cell pattern. The patient is free of disease after 20 months of surgical procedure.

Conclusion: Although there isn't any antibody that confirms the diagnosis of EMC, due to the difficulty to make a correct diagnostic of this lesion by cytology, we have highly recommended the use of immunocytochemistry assay as an important tool to confirm the double-cell pattern, which in together with a clinical course may help in the diagnostic of EMC. Cytology and histology correlation are rarely reported.
\end{abstract}

Keywords: Fine needle aspiration; Carcinoma; Salivary glands; Immunohistochemistry

\section{Highlighted Boxes}

\section{Established facts}

Biphasic pattern of EMC is a relevant cytological feature to orientate the diagnosis of this exceedingly rare malignant salivary gland tumor.

\section{Novel insights}

Nonspecific antibodies such as CD117 and P-63, can help us to make a good diagnostic approach in cytological smears.

\section{Introduction}

Epithelial-Myoepithelial Carcinoma (EMC) is a rare malignant salivary gland tumor which chiefly occurs in the parotid gland, representing about $1 \%$ of all neoplasm of salivary gland [1]. Donath et al. [2] in 1972 introduced the term EMC by noting the myoepithelial component as an integral part of the tumor. EMC occurs mainly in the parotid gland, but it has been also described in the submandibular gland, in the minor salivary glands and extra oral areas [3-6]. It is more commonly seen in females, with a peak incidence in the seventh decade [7]. We report a case of EMC in an 86 year old female who complained of a bulky mass on her right parotid. A cytological and histological correlation was made.

\section{Case Report}

An 86 year old female with a history of painless longstanding bulky lesion over her right parotid gland. Since, last 5 months to date she noted a fast growing. Cervical adenopathy and her right facial nerve function were unaffected. Ultrasonography and computed tomography of the head and neck revealed a non-homogeneously solid mass measuring $6.5 \times 4.5 \mathrm{~cm}$ in her right parotid gland with a skin protuberance, an external jugular vein displacement and possibility of a sternocleidomastoid muscle infiltration. There wasn't evidence of jaw affectation. The tumor's interface with the parotid gland was clearly defined. Clinically and radiologically the tumor suggested a malignant neoplasm. The patient underwent Fine Needle Aspiration
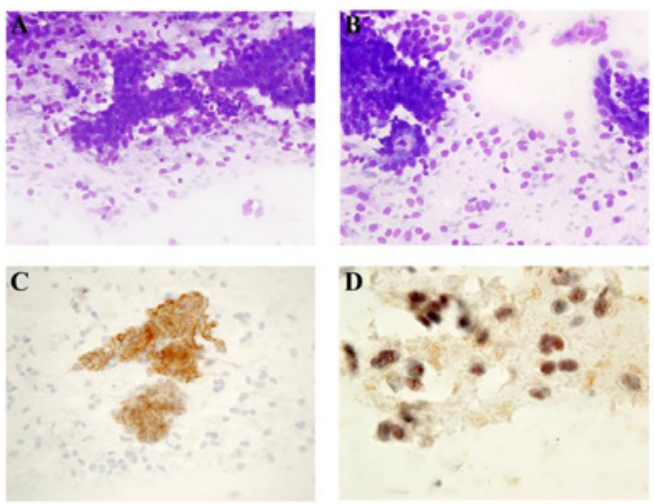

Figure 1: a-b: Cytosmear showing a pseudopapillary structures with a myoepithelial background. Biphasic pattern, central low-cuboidal ductal cells surrounded by clear myoepithelial cells; May-GrünwaldGiemsa, x400. c) CD117 antibody highlighting the ductal component; Immunoperoxidase stain, $x 400$. d) P-63 antibody, nuclear positivity in myoepithelial cells; Immunoperoxidase stain, x1000.

*Corresponding author: Iván Fernández-Vega, Pathology Department Central University Hospital of Asturias, 33006, Oviedo, Spain, E-mail: ivan.fernandez@sespa.princast.es

Received December 19, 2012; Accepted December 28, 2012; Published December 31, 2012

Citation: Fernández-Vega I, Fuentes-Martínez N, Mendoza GE, Santos-Juanes J, Fresno-Forcelledo F (2012) Epithelial-Myoepithelial Carcinoma of Parotid Gland: A Cytological Challenge with Histological Correlation. J Cytol Histol 3:156. doi:10.4172/2157-7099.1000156

Copyright: (c) 2012 Fernández-Vega I, et al. This is an open-access article distributed under the terms of the Creative Commons Attribution License, which permits unrestricted use, distribution, and reproduction in any medium, provided the original author and source are credited. 
Citation: Fernández-Vega I, Fuentes-Martínez N, Mendoza GE, Santos-Juanes J, Fresno-Forcelledo F (2012) Epithelial-Myoepithelial Carcinoma of Parotid Gland: A Cytological Challenge with Histological Correlation. J Cytol Histol 3:156. doi:10.4172/2157-7099.1000156

Cytology (FNAC) from mass with 23G needle. Cytology revealed both epithelial and stromal components. Cells were frequently arranged in pseudopapillary formations, with slightly eosinophilic stromal cores on May-Grünwald-Giemsa (MGG) stain (Figure1a). Epithelial cells were in clusters or singles, with spindle cells in a scanty myxoid stromal background (Figure 1b). There wasn't evidence of cellular atypia so, immunocytochemistry was performed in order to rule out the possibility of malignant tumor. Eventually, immunocytochemistry highlighted the biphasic nature of this tumor with epithelial cells positive for CD 117 (Figure 1c) and myoephitelial cells positive for P-63 (Figure 1d). Clinical course together with cytological findings were consistent with a biphasic malignant parotid gland neoplasm called EMC. A right parotidectomy was performed including adjacent soft tissue and skin (Figure 2a).

Cutting sections from formalin fixed tumour did show a poorly circumscribed greyish mass, arranged in a globular pattern with a haemorrhagic core, measuring $6 \mathrm{~cm}$ in higher diameter (Figure 2b). Histopathology sections displayed a normal parotid structure and a uniform nesting arrangement of tumor cells being separated by a thin fibrous connective tissue capsule (Figure 3a). There were two cell types, an outer layer of clear myoepithelial cells and an inner layer of cuboidal eosinophilic duct-like cells. These cells were further enveloped on outside by a well defined basement membrane material (Figure 3b). There wasn't evidence of nuclear atypia but some mitotic figures were seen.

Immunohistochemistry assay was also made. Epithelial cells were strongly positive for cytokeratin 8 (Figure 3c) and CD 117 (Figure 3f). Myoephitelial cells did stain with smooth muscle actin (Figure $3 \mathrm{~d}$ ) and P-63(Figure 3e). S100 was also positive in myoephitelial cells showing
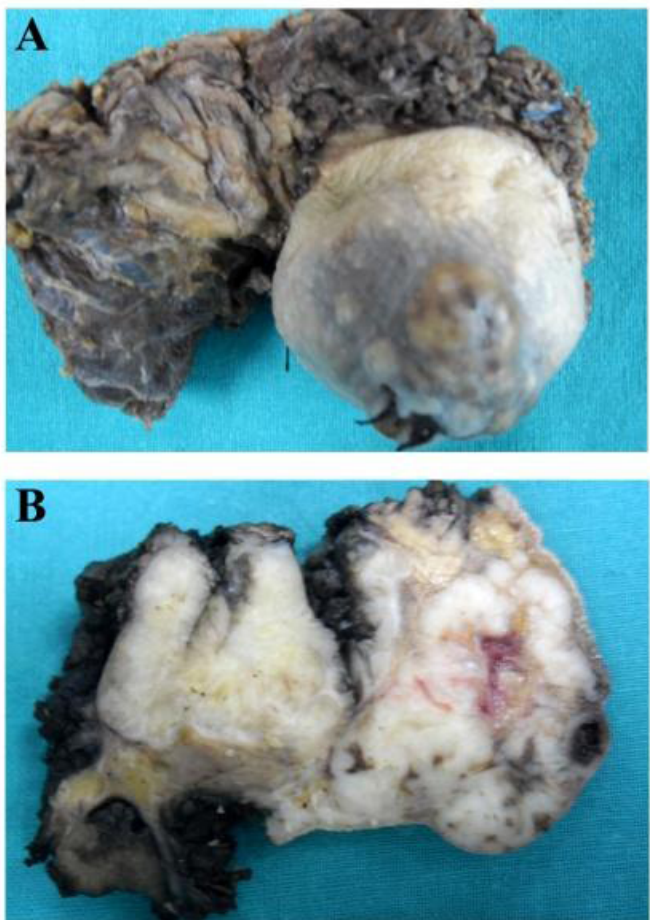

Figure 2: a) A total right parotidectomy including adjacent soft tissue and skin. b) Tumor features showing a bad-bordered lobulated mass with a gray/ yellowish surface and some hemorrhagic areas. Non-tumoral parotid gland is illustrated in the right upper part.
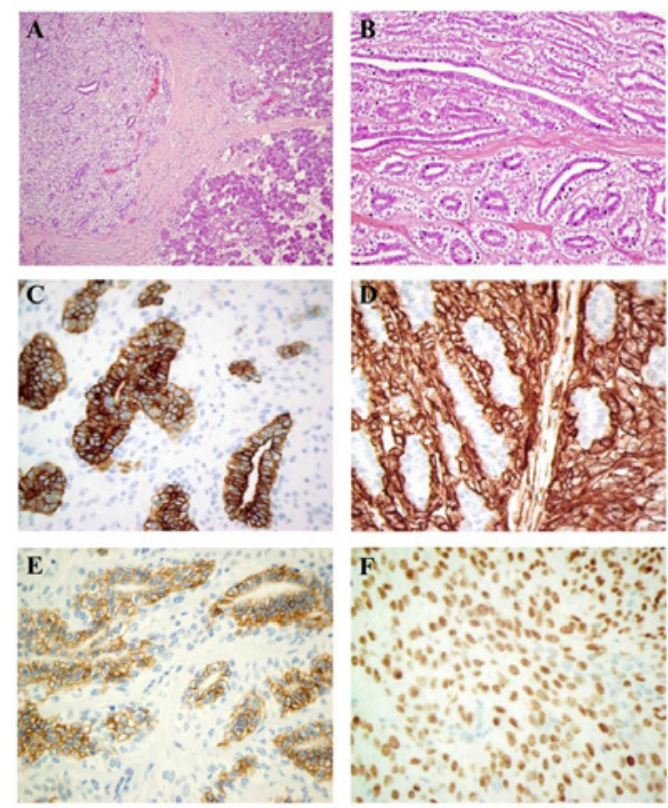

Figure 3: Histology. a) Normal parotid gland separated from tumor by connective tissue capsule; H\&E, $x 100$. b) Biphasic pattern, an inner ducta cells and outer clear myoepithelial cells; H\&E, x200. c) Cytokeratin 8 positivity in the epithelial component; Immunoperoxidase stain, x400. d) Smooth muscle actin positivity in the myoepithelial component; Immunoperoxidase stain, $x 400$. e) CD117 present in the epithelial groups; Immunoperoxidase stain $\mathrm{x} 400$. f) P-63 positivity in the myoepithelial cells nuclei; Immunoperoxidase stain, $\mathrm{x} 600$

nuclear and cytoplasmatic staining. Both groups of cells were negative for GFAP and PSA. Ki-67 was up to $20 \%$ mainly in the myoepithelial component. Thus, the final diagnosis of EMC of the right parotid gland was made. Since the surgery the patient has done well, without evidence of either local recurrence or metastases.

\section{Discussion}

Firstly described by Donath et al. in 1972 [2], EMC wasn't included in the World Health Organization classification of salivary gland tumors until 1991 [8]. Higher incidence is in older persons with a female predominance, and affect principally the parotid gland, more than the others salivary glands [7]. Furthermore, most patients tend to present an asymptomatic enlarging mass from weeks to months, whereas others exhibited signs of malignancy such as pain or facial paralysis.

Although radiological signs can approach to the malignancy, EMC is a pathological challenge particularly when the diagnostic is not suspected. In cytology smears differential diagnosis must be done with myoepithelioma, pleomorphic adenoma, monomorphic adenoma, adenoid cystic carcinoma and polymorphous low grade adenocarcinoma. Klijanienko et al. have published a quantitative differential diagnosis of EMC on cytology smears taking into account both , stroma and cells features, such as papillary formations, clear cells, cuboidal/basal cells, plasma-shape myoepithelial cells, squamous cells, cellular atypia, chondromixoid stroma, mucoid stroma, hyaline deposits and crystalloids. Sometimes these characteristics are overlapping between one tumor and another, however up to $84,6 \%$ of EMC are diagnosed as suspicious/malignant as this authors demonstrated. In the other hand, only $7.7 \%$ of cases were diagnosed as a benign tumor such as pleomorphic adenoma. Finally, they conclude that failure to 
distinguish between these entities is not dramatic, because all of them lead to surgical excision [9].

In the way to improve our knowledge about salivary gland tumors, we could find in the English literature that Seethala et al. recently published a frequent positivity $(69,2 \%)$ of c-kit (CD117) in EMC [10]. However, Andreadis et al. [11] have lately demonstrated that CD117 was also expressed in a wide group of malignant salivary gland tumors, such as adenoid cystic carcinoma, acinar cell carcinoma and basal cell adenocarcinoma. By the way, they have also seen a CD117 expression in benign salivary gland pathology, for example inflammatory disease.

In order to differentiate EMC from others malignancies, is important to take into account that biphasic nature (epithelial and myoepithelial) is the most relevant finding. This pattern can be present in smears, but it's better seen in histology and is characterized by a tubular or ductal structures composed of basal myoepithelial and luminal epithelial cells, these latest look like normal intercalated salivary gland ducts. We confirmed the double-cell pattern on smear and on histology sections. In the former, immunocytochemistry displayed a strong positivity for CD117 (Figure 1c) and strong nuclear positivity for P-63 (Figure 1d) in myoepithelial cells. In formalin fix tissue, immunohistochemistry revealed a positivity for cytokeratin 8 (Figure 3c) and CD117 (Figure 3f), and intense dye with smooth muscle actin (Figure 3d) and P-63 (Figure 3e) in the myoephitelial cells. Although PSA is considered highly specific marker for prostate carcinoma, several authors have demonstrated focal immunostaining for PSA in pleomorphic adenoma, mucoepidermoid carcinoma, and ductal carcinoma of salivary gland [12]. Aberrant expression of PSA was recently described by Venetia et al. in one case of dedifferentiated EMC [13]. In the present case PSA was negative.

In conclusion, we remark the biphasic pattern of EMC as a cytological strategy to orientate the diagnosis of this exceedingly rare malignant salivary gland tumor; however, non-specific antibodies can help us to make a good diagnostic approach, although they may be useful. Our patient is free of disease since surgery.

\section{References}

1. Ellis GI, Auclair PL (1996) Tumors of the salivary glands: in malignant epithelial tumors. Rosai J (ed). Washington, DC: Armed Forces Institute of Pathology.

2. Donath K, Seifert G, Schmitz R (1972) Diagnosis and ultrastructure of the tubular carcinoma of salivary gland ducts: Epithelial-Myoepithelial Carcinoma of the intercalated ducts. Virchows Arch A Pathol Anat 356: 16-31.

3. Maurer MH, Gartenslager S, Dietrich C (2009) Giant Epithelial-Myoepithelia Carcinoma of the parotid gland. Clin Imaging 33: 237-239.

4. Teppo H, Paronen I (2008) Epithelial-Myoepithelial Carcinoma in minor salivary gland of the hard palate. J Craniofac Surg 19: 1689-1691.

5. Kumai Y, Ogata N, Yumoto E (2006) Epithelial-Myoepithelial Carcinoma in the base of the tongue: a case report. Am J Otolaryngol 27: 58-60.

6. Harada H, Kashiwagi SI, Fujiura H, Kusukawa J, Morimatsu M (1996) EpithelialMyoepithelial Carcinoma: report of a case arising in the nasal cavity. J Laryngol Otol 110: 397-400

7. Noel S, Brozna JP (1992) Epithelial-Myoepithelial Carcinoma of salivary gland with metastasis to lung: report of a case and review of the literature. Head Neck 14: 401-406.

8. Seifert G, Donath K (1996) Multiple tumors of the salivary glands: terminology and nomenclature. Eur J Cancer 32B: 3-7.

9. Klijanienko J, Vielh P (1998) Fine-Needle sampling of salivary gland lesions VII. Cytology and histology correlation of five cases of Epithelial-Myoepithelial Carcinoma. Diagn Cytopathol 19: 405-409.

10. Seethala RR, Barnes EL, Hunt JL (2007) Epithelial-Myoepithelial Carcinoma: a review of the clinicopathologic spectrum and immunophenotypic characteristics in 61 tumors of the salivary glands and upper aerodigestive tract. Am J Surg Pathol 31: 44-57.

11. Andreadis D, Epivatianos A, Poulopoulos A, Nomikos A, Papazoglou G, et al (2006) Detection of C-KIT (CD117) molecule in benign and malignant salivary gland tumors. Oral Oncol 42: 57-65.

12. Krieken V (1993) Prostate marker immunoreactivity in salivary gland neoplasms A rare pitfall in immunohistochemistry. Am J Surg Pathol 17: 410-414.

13. Sarode VR, Truelson J, Zaidie M (2010) Dedifferentiated Epithelial-Myoepithelial Carcinoma of the parotid gland with aberrant expression of Prostate Specific Antigen: a case report. Int J Surg Pathol 18: 401-405. 